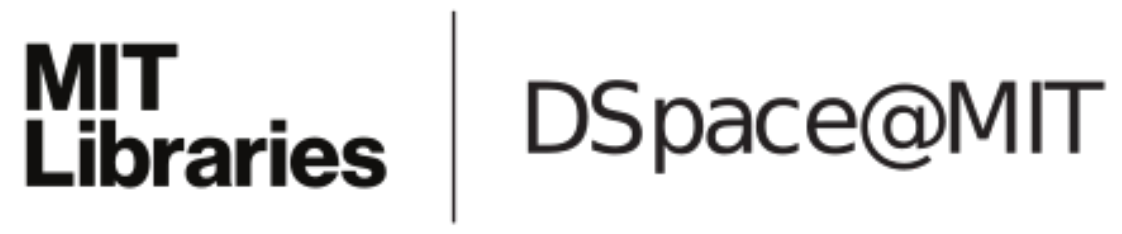

MIT Open Access Articles

A study of soot formation in a rapid compression machine at conditions representative of cold-fast-idle in spark ignition engines

The MIT Faculty has made this article openly available. Please share how this access benefits you. Your story matters.

Citation: Ketterer, Justin and Wai K. Cheng. "A study of soot formation in a rapid compression machine at conditions representative of cold-fast-idle in spark ignition engines." International Journal of Engine Research, May 2018.

As Published: $10.1177 / 1468087418777663$

Publisher: SAGE Publications

Persistent URL: https://hdl.handle.net/1721.1/121538

Version: Author's final manuscript: final author's manuscript post peer review, without publisher's formatting or copy editing

Terms of use: Creative Commons Attribution-Noncommercial-Share Alike 


\title{
A Study of Soot Formation in a Rapid Compression Machine at Conditions Representative of Cold-fast-idle in Spark Ignition Engines
}

\section{Justin E. Ketterer and Wai K. Cheng}

\begin{abstract}
The soot yield, defined as the ratio of the soot mass to the carbon mass in the fuel, for the homogeneous combustion of a rich fuel-air mixture has been measured in a rapid compression machine using the laser light extinction method. The temperature and pressure conditions are representative of those in spark-ignition direct-injection engines at cold-fast-idle. The fuels used are a certification gasoline (with $28 \%$ aromatic content by volume) and a blend of the gasoline with toluene (the blend had $40 \%$ aromatic content by volume) so that the sensitivity of soot formation to the fuel aromatic content could be assessed. Beyond a threshold fuel equivalence ratio $(\phi)$ value, the soot yield increases exponentially with $\phi$. The soot yield of the gasoline-toluene blend is 4 to 6 times higher than that of the gasoline. The soot yield decreases exponentially with temperature, by a factor of 0.58 for every $10 \mathrm{~K}$ increase in temperature. In the $657 \mathrm{~K}$ to $695 \mathrm{~K}$ temperature range, the threshold $\phi$ value increases linearly from 2.45 to 2.65 , at a rate of 0.1 point per $10 \mathrm{~K}$ rise in temperature. This temperature dependence is insensitive to the charge density.
\end{abstract}

\section{Introduction:}

In preparation for Euro 6c/d and China 6 emissions standards, automakers have made tremendous strides in their efforts to mitigate particulate matter (PM) emissions from spark ignition (SI) engines. This is particularly true in the case of direct injection (DI) engines, which, in early incarnations, were found to emit PM at higher rates than modern diesel engines equipped with particulate filters [1]. Many of the improvements that have been realized were enabled through empirical research and development. Carefully designed engine studies, including the use of optical diagnostics [2], provided crucial steps in formulating a clear understanding of the conditions that lead to the formation of soot in-cylinder [3]. Based on these studies, engine designers have been able to devise injectors that minimize the impingement of fuel on combustion chamber surfaces and which enable adequate mixing of the fuel/air charge. Calibrators also know which operating regimes to avoid when preparing steady-state and transient calibration maps. Further, studies have identified injector tip deposits as a major source of soot and have made strides in understanding the formation mechanisms [4]. Injector suppliers continue to make incremental improvements to their hardware, reducing the leakage rates and propensity for coking of their injectors. These technology advancements have 
significantly lowered the direct injection spark ignition (DISI) engine particulate emissions.

Going forward, the addition of predictive soot formation modelling to CFD models for engine development will be increasingly valuable to the design of new combustion systems for SIDI engines. Modelling is intended to support the design of engines that meet emissions standards on the first attempt. These models, under continuing development, are complex, combining detailed flow simulation with detailed chemical analysis. Calibration of these models via engine measurements is difficult and indirect, as measurements of PM in engine exhaust are not well controlled and sufficiently repeatable. Further, these measurements provide only a measure of the overall emissions in a cycle. They do not elucidate the locations or mechanisms of formation in-cylinder. To establish data for soot formation model validation, a simple and repeatable combustion process is sought.

An important revelation on the soot formation process in DISI engines [3] is that soot is not formed in a diffusion flame, which had been hypothesized to exist from the "pool fire" observed in optical engines $[5,6]$. The reality is the fuel rich region is embedded in the burned gas which contains little oxygen and which cannot support a flame. Therefore, the soot is formed in the fuel rich region via bulk reaction and not in a flame.

A large body of soot measurements exists in the literature [7, 8, 9]. However, engine exhaust measurements [10], being the aggregated result from a cycle, is inadequate for elucidating the detailed soot formation process. As discussed above, soot measurements from diffusion flames are not appropriate for GDI. Furthermore, much of the well controlled soot measurements have been done with neat fuel compounds $[8,11]$ which lack the complexity of real gasolines. There is an effort to represent gasoline by a collection of surrogate molecules [12]. To check the validity of the representation, data from a real gasoline is needed.

To address the above issues, a rapid compression machine (RCM) is used for this study. The experimental condition is carefully controlled with repeatable homogeneous mixture compositions and temperature-time histories. The reaction takes place in the bulk. Soot formation is measured by light extinction method $[13,14]$.

The baseline fuel is a certification gasoline (Haltermann HF0437 EPA EEE Tier II certification fuel). Because aromatics have been observed to play a strong role in correlating fuel species with DISI engine soot emissions $[15,16,17,18]$, additional tests have been performed with the addition of $20 \%$ toluene, by volume, to the baseline gasoline. Toluene has been chosen as the additional aromatic because it is a dominant aromatic in gasolines. The intent is to assess the difference in the soot formation characteristics with the aromatic fraction of the fuel. The results constitute a set of data well-suited for validating soot formation models, and provide insight into the fuel-air mixture characteristics of soot forming regions in engines. A useful output of this work is the threshold equivalence ratio for soot formation because this value determines the incylinder mixing requirement for soot suppression. 


\section{Experimental Setup and Methods:}

\section{Rapid Compression Machine:}

An RCM is a piston-cylinder device commonly used to study fuel ignition characteristics under conditions representative of those in an engine. The RCM compresses a uniform mixture of fuel and oxidant in a combustion chamber. The rapid rise in temperature and pressure associated with compression causes the mixture to auto-ignite. The piston is held in position pneumatically, enabling a constant volume combustion event.

MIT's horizontal RCM [19] was used for this study. It is a single piston device with a maximum stroke of $20.3 \mathrm{~cm}$. The stroke is variable, but it was held constant at $20.3 \mathrm{~cm}$ for this study at a compression ratio of 11.6:1. The RCM consists of three main sections: the pneumatic driving section, the hydraulic motion control section and the combustion chamber (see Figure 1). The pneumatic cylinder in the driving section provided the motive force for the piston. It was connected to a supply of compressed nitrogen at a pressure of $17 \mathrm{bar}$. This pressure was sufficient to hold the piston in the fully compressed position through the duration of the combustion event. The compression time was approximately $15 \mathrm{~ms}$. The machine and its operation are detailed in Ref. [19].

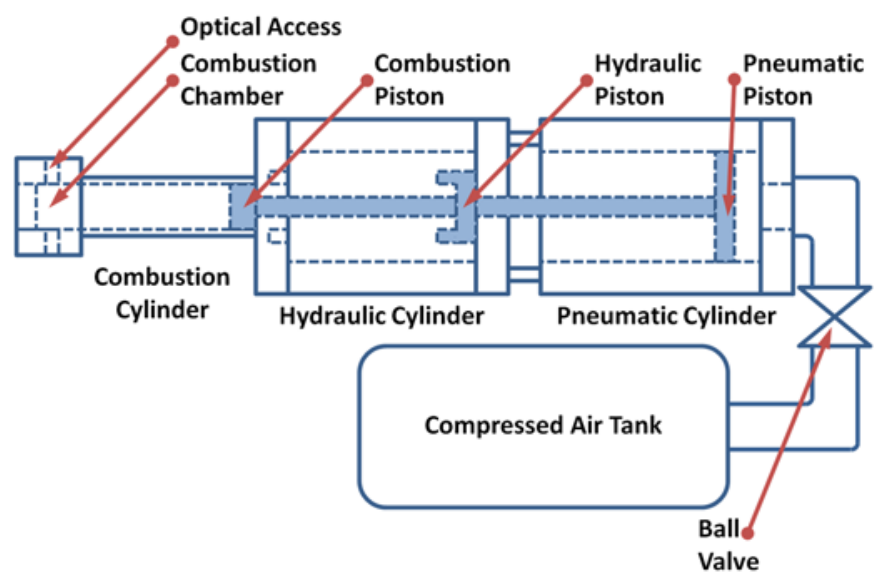

Figure 1: Schematic of the Rapid Compression Machine

The cylinder pressure was measured using a Kistler 6125A transducer and a Kistler $5010 \mathrm{~b}$ charge amplifier along with a National Instruments PCI-6025E data acquisition card and a National Instruments BNC 2090 terminal block. The combustion chamber temperature was controlled using heating tape mounted around the combustion section of the RCM.

\section{Optical setup:}

The soot concentration in the combustion chamber was measured using the light extinction method, by which the change in the transmission of laser light through the combustion event is related to the soot concentration present in the combustion chamber. 
Optical access for the laser is obtained by installing two fused silica windows perpendicular to the axis of the RCM, through the centre of the combustion chamber.

The laser was a $30 \mathrm{~mW}$ He-Ne laser at a wavelength of $632.8 \mathrm{~nm}$. The laser beam was directed through the centre of the combustion chamber. An integrating sphere was used to convert the laser light into a diffuse light source so that the detection was less susceptible to beam wander due to vibration of the apparatus. A photomultiplier tube (PMT) was used as the light sensor. The PMT was equipped with a $632.8 \mathrm{~nm}$ line filter to suppress light from other sources (such as that from the combustion event). The PMT was also equipped with a collimator to keep the incident light perpendicular to the filter face. This was important because the effectiveness of the line filter decreases sharply as the light beams stray from perpendicular. The optical system setup is shown in Figure 2.

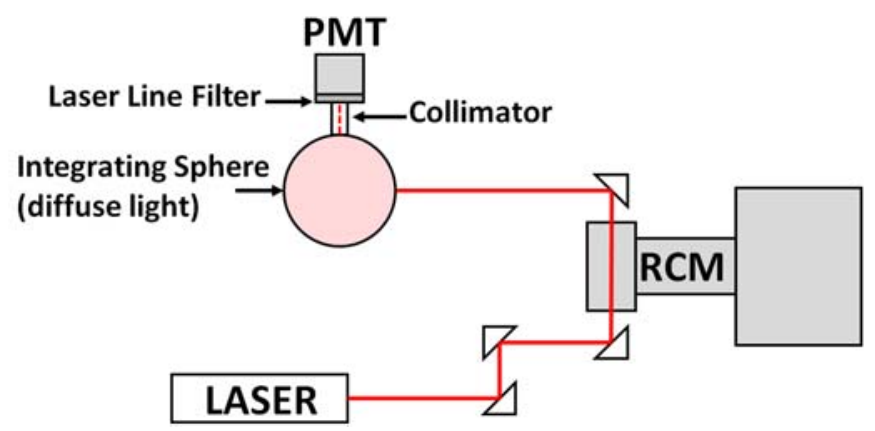

Figure 2: RCM Optical Soot Measurement Setup

\section{Light Extinction Method:}

The soot concentration can be measured based on the change in light intensity during a combustion event. In this case, the laser was the light source, and the light was attenuated by the soot present along the laser line-of-sight through the combustion chamber. The volume fraction of soot can be calculated using the following equation $[13,14]$ :

$\mathrm{C}_{\mathrm{v}}=\frac{\lambda}{6 \pi \mathrm{L} \operatorname{Im}\left\{\frac{\mathrm{m}^{2}-1}{\mathrm{~m}^{2}+2}\right\}} \ln \left(\frac{\mathrm{I}}{\mathrm{I}_{0}}\right)$,

where $C_{v}$ is the volume fraction of soot, $\lambda$ is the light wavelength, $L$ is the length of light travel through the combustion chamber, $\mathrm{m}$ is the complex refractive index of the soot, $\mathrm{I}$ is the attenuated light intensity, and $\mathrm{I}_{0}$ is the incident light intensity.

The volume fraction of soot in the cylinder was used to calculate a soot yield, which is defined as the mass of soot normalized by the mass of fuel carbon present in the unreacted mixture. The soot yield (SY) is calculated using the following equation:

$\mathrm{SY}=\frac{\rho_{\mathrm{S}} \mathrm{C}_{\mathrm{v}}}{\mathrm{M}_{\mathrm{C}}[\mathrm{C}]_{\mathrm{comp}}}$, 
where $\rho_{\mathrm{s}}$ is the density of soot, $\mathrm{C}_{\mathrm{v}}$ is the volume fraction of soot, $\mathrm{M}_{\mathrm{C}}$ is the molecular mass of carbon and $[\mathrm{C}]_{\text {comp }}$ is the molar concentration of fuel carbon in the unburned mixture upon compression [14].

\section{Mixture preparation:}

The mixture was prepared in a mixing chamber of approximately 10 times the volume of the RCM displacement. The design and operation of the mixing chamber are described in detail in Ref. [20]. The mixture comprised fuel, oxygen, nitrogen and argon. The latter was used to control the compression temperature by displacing some of the nitrogen to obtain a change in the ratio of specific heats of the mixture without changing the RCM initial temperature. The chamber was evacuated before any new mixture was prepared. The liquid fuel was introduced to the evacuated chamber by injection through a vacuum septum. The fuel evaporated quickly because of the low system pressure. The oxygen, nitrogen and argon were then metered-in manometrically. The mixture in the chamber was circulated by an internal fan to ensure mixture uniformity. The vacuum pass-through for the fan was rated to a differential pressure of up to 2 bar (yielding a maximum mixture pressure of approximately 3bar). For these experiments, however, the mixtures were prepared at a maximum pressure of approximately $1.2 \mathrm{bar}$. This was sufficient to permit multiple runs with a single mixture. To prevent the condensation of fuel species when the chamber was heated to a temperature of $80^{\circ} \mathrm{C}$. At this temperature and pressure, the partial pressures of the fuel constituents (computed using the fuel speciation data and mixture stoichiometry) are well below the saturation vapour pressures of the respective fuel species (by more than a factor of 5). Throughout the mixture transfer and equilibration processes, the system pressures were monitored to ensure there were no air leaks into the mixture.

\section{Experimental design and measurement procedure}

The desired temperature and pressure at the end of the compression event were chosen to replicate the conditions of the end gas in a downsized, boosted, direct injected SI engine at a cold-idle condition of $1200 \mathrm{rpm}$ and 2 bar net indicated mean effective pressure. This operating condition was of interest because the cold-start and catalyst heating period of emissions cycles account for a significant portion of the total on-cycle particulate matter emissions [21]. A quasi-dimensional simulation was performed using the MIT engine simulation code [22] to determine the temperature-pressure trajectory of the end gas in an engine. The initial conditions of the mixture were then chosen to yield these conditions upon compression. Measurements were taken at a range of charge densities that could be expected in the end gas region during the cold-fast-idle engine operating regime. The end-gas is the region of interest as it has been demonstrated that fuel vapour plumes near cylinder surfaces are a source of soot formation after the completion of the main combustion event [3]. The rich equivalence ratios examined in this study are representative of the local equivalence ratios of these soot-forming fuel plume regions in downsized-boosted spark ignition engines. Fuel evaporating from cylinder surfaces can result in locally rich mixtures even though the global equivalence ratio will be very close to unity. 
Because of heat loss to the combustion chamber walls, a thin thermal boundary layer develops. The thickness of this boundary layer is of the order of a fraction of a millimetre. In addition, the scraping of the piston along the chamber walls gives rise to a roll up vortex [23]. This is a thin layer of charge at a lower temperature than the bulk charge, but not attached to the wall. However, the major part of the charge still comprises an adiabatic core in which the chemistry takes place. The temperature of this adiabatic core is calculated via the assumption of isentropic compression of the charge from the initial temperature and pressure to the measured pressure at the end of compression.

After preparing the mixture in the mixing vessel and allowing it to equilibrate with the mixing fan running, the mixture was admitted to the combustion chamber (with the piston fully retracted). There, the temperature of the charge was allowed to equilibrate with the temperature of the combustion chamber. Compression commenced when the hydraulic fluid pressure was released. The data acquisition system was triggered by the increase in pressure at the beginning of compression. The pressure and PMT output were measured for 1 second, beginning at $50 \mathrm{~ms}$ before the trigger, using the pre-trigger acquisition mode.

\section{Experimental matrix}

This study examined the effects of equivalence ratio, fuel aromatic content, charge density (end of compression molar charge concentration) and temperature (end of compression temperature) on the formation of particulate matter.

The base fuel was EPA EEE tier II certification fuel (Haltermann HF0437) which had no oxygenate content and $28 \%$ aromatics by volume according to the product information sheet. To assess the effect of aromatics on PM formation, $20 \%$ by volume of toluene was added to the fuel so that the resulting fuel blend had an aromatic content of $40 \%$ by volume.

There were three sets of experiments. In the first set, soot yields were measured for the two fuels as a function of fuel equivalence ratios from 2 to 3 in steps of 0.1 . The targeted temperature at the end of compression was $750 \mathrm{~K}$. The temperature of the adiabatic core computed from the observed pressure was approximately $695 \mathrm{~K}$. Two compression densities were used: $0.14 \mathrm{kmol} / \mathrm{m}^{3}$ and $0.16 \mathrm{kmol} / \mathrm{m}^{3}$. The corresponding pressures at the end of compression were 8.09 bar and 9.25 bar. At each condition, the experiment was repeated 3 times.

The second set of experiments was a simple temperature sweep at a constant equivalence ratio and charge density. The equivalence ratio was 2.5 and the charge density was 0.16 $\mathrm{kmol} / \mathrm{m}^{3}$. The initial charge temperature was held constant at $373 \mathrm{~K}$. The temperature differences were obtained by varying the argon/nitrogen ratio in the inert fraction of the mixture from fully nitrogen to fully argon. The resultant change in the ratio of specific heats of the mixture permitted a range of temperatures at the end of compression from approximately $640 \mathrm{~K}$ to $730 \mathrm{~K}$. This experiment was only run for the base gasoline fuel. 
The third set of experiments was to establish a sooting threshold for a rich mixture; i.e. the fuel equivalence ratio beyond which a significant amount of soot was formed. The soot yield (SY) at the "sooting boundary" was chosen to be high enough for reliable detection, and low enough for the boundary to be meaningful. The value used was $\mathrm{SY}=3 \times 10^{-4}$. The sooting threshold experiments were performed for temperatures from approximately $650 \mathrm{~K}$ to $700 \mathrm{~K}$ and densities of $0.12,0.14$ and $0.16 \mathrm{kmol} / \mathrm{m}^{3}$. In each case, the equivalence ratio was swept until the threshold soot yield was bounded by the measured data. The threshold equivalence ratio was then linearly interpolated between the measured data points.

\section{Results:}

A representative measurement of pressure during RCM operation is shown in Figure 3. The first pressure increase corresponds to the compression event. The ignition delay period follows. There is a slight increase in pressure during this period due to the heat release in the pre-ignition chemistry. At approximately $110 \mathrm{~ms}$, the main combustion event occurs, resulting in a rapid pressure increase. Following the combustion event, the pressure decreases due to heat loss to the combustion chamber walls.

The corresponding light transmission through the combustion chamber is shown in Figure 4. The noise in the trace is due to mechanical vibrations and the corresponding beam walking, the effect of which has been minimized by using an integrating sphere. The rapid drop in light transmission coincident in time with the main combustion event was due to the formation of soot which obscured the laser beam. Despite the use of the integrating sphere, the vibration-induced disturbance on the transmission signal took approximately $50 \mathrm{~ms}$ after the main pressure rise event to settle out to steady-state. This steady state value was used to determine the soot yield.

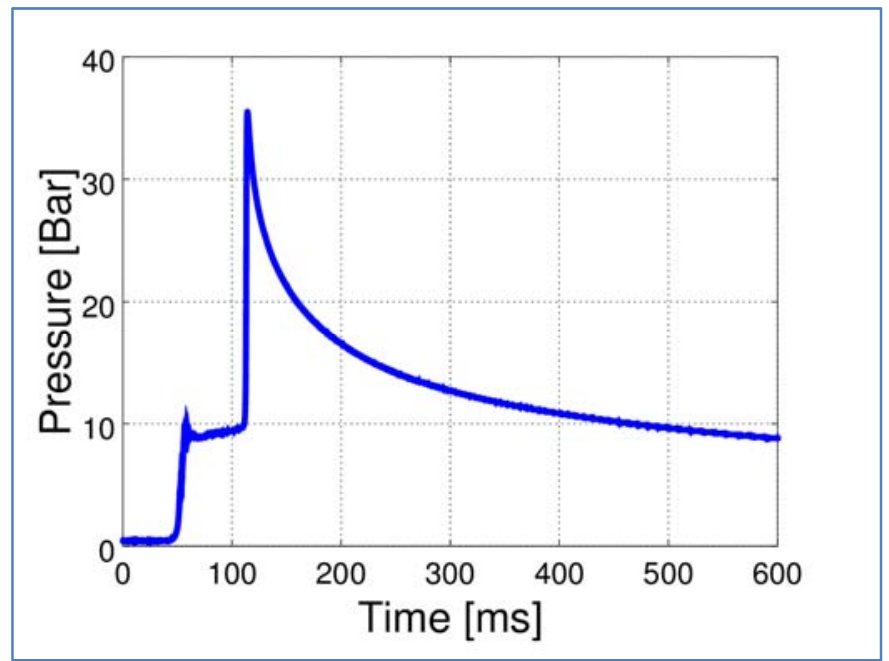

Figure 3: Representative Pressure vs. Time Trace; $\phi=2.7$; compressed density $=$ $0.16 \mathrm{kmol} / \mathrm{m}^{3}$; temperature $=695 \mathrm{~K}$. 


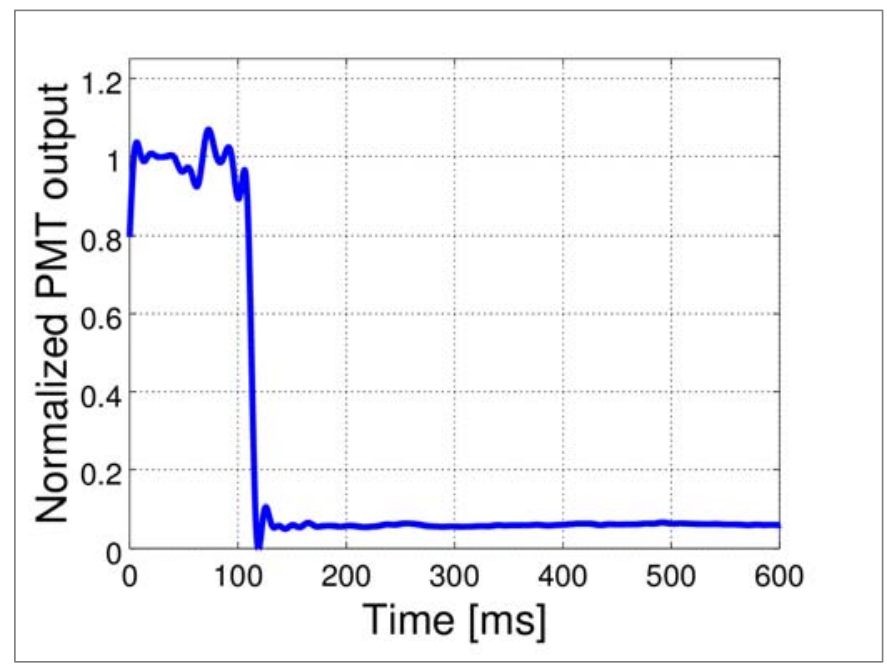

Figure 4: Representative Laser Transmission vs. Time; $\phi=2.7$; compressed density $=$ $0.16 \mathrm{kmol} / \mathrm{m}^{3}$; temperature $=695 \mathrm{~K}$.

\section{Soot yield as a function of equivalence ratio}

The first set of experiments measured the soot yield as a function of the fuel equivalence ratio $(\Phi)$ for gasoline and a mixture of gasoline and $20 \%$ (by volume) toluene. The aromatic content (by liquid volume) of the former fuel was $28 \%$; the latter was $40 \%$. The experiments were repeated at two different charge densities $\left(0.14 \mathrm{kmol} / \mathrm{m}^{3}\right.$ and 0.16 $\mathrm{kmol} / \mathrm{m}^{3}$ ). These charge densities are representative of the charge density of the end gas in a modern, turbocharged, direct injected engine during fast-idle for catalyst light-off. The target temperature at the end of compression remained constant at $750 \mathrm{~K}$ (The actual temperature of the core gas was calculated from the measured pressure to be approximately $695 \mathrm{~K})$.

Figure 5 shows the light attenuation versus $\Phi$ for the gasoline and the gasoline/toluene mixture at a charge density of $0.16 \mathrm{kmol} / \mathrm{m}^{3}$ (corresponding to a pressure of $9.25 \mathrm{bar}$ ). For both fuels, soot began to form and obscured the light when $\Phi$ was greater than 2 . The attenuation increased with increasing $\Phi$. The combustion chamber became optically opaque when the equivalence ratio approached 3 . Throughout the period of rapid increase in opacity, the gasoline/toluene blend had significantly higher light attenuation.

The soot yield versus equivalence ratio relationship is shown in Figure 6. The error bars (at $95 \%$ confidence interval of repeating the measurements three times) demonstrate the limits of the experiment at high attenuation, where the logarithmic term in Eq.(1) is very sensitive to the transmission.

The soot yield data in Figure 6 are re-plotted on a semi-log scale in Figure 7. Beyond the soot threshold of approximately $\Phi=2$, the soot yield first increases exponentially with $\Phi$, and then tapers out at $\Phi$ larger than approximately 2.7. Similar soot yield behavior has been observed in rich premixed flames [8]. In the range of $\Phi$ between 2.2 and 2.6, where the soot yield increases exponentially with $\Phi$, the soot yield increases by a factor of 2.5 
for every 0.1-point increase in $\Phi$. This rate of increase is the same for both the gasoline and the gasoline-toluene mixture. Averaged over the range of $\Phi$ from 2.2 to 2.6, the gasoline-toluene soot yield was approximately 6 times that of the gasoline only soot yield.

The soot yield versus equivalence ratio at a lower density $\left(0.14 \mathrm{kmol} / \mathrm{m}^{3}\right.$; corresponding to a compression pressure of $8.09 \mathrm{bar}$ ) is shown in Figure 8 . The soot yield behavior is similar to that of the higher density case of Figure 7. The soot yield also increases, for both the gasoline and the gasoline-toluene mixture, by the same factor of 2.5 for every 0.1 -point increase in $\Phi$. The increase in soot yield attributed to toluene addition at the same $\Phi$ is lower in this case. Over the range of $\Phi$ from 2.2 to 2.6, the soot yield increased by an average factor of approximately 4 with the toluene addition.

Comparing the soot yields at the two charge densities reveals that the values for the toluene/gasoline mixtures are essentially the same at both charge densities; see Figure 9. However, a difference was observed between the gasoline-only curves; see Figure 10. It is this difference that accounts for the density dependence of the difference in soot yield when the two fuels were compared.

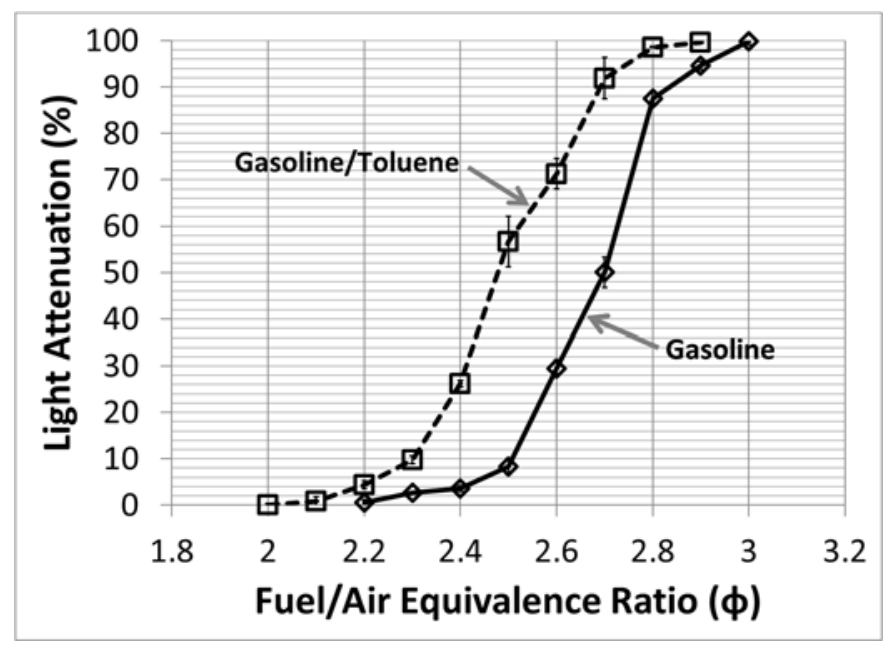

Figure 5: Light attenuation versus equivalence ratio (charge density $=0.16 \mathrm{kmol} / \mathrm{m}^{3}$, temperature $=695 \mathrm{~K}$ ) 


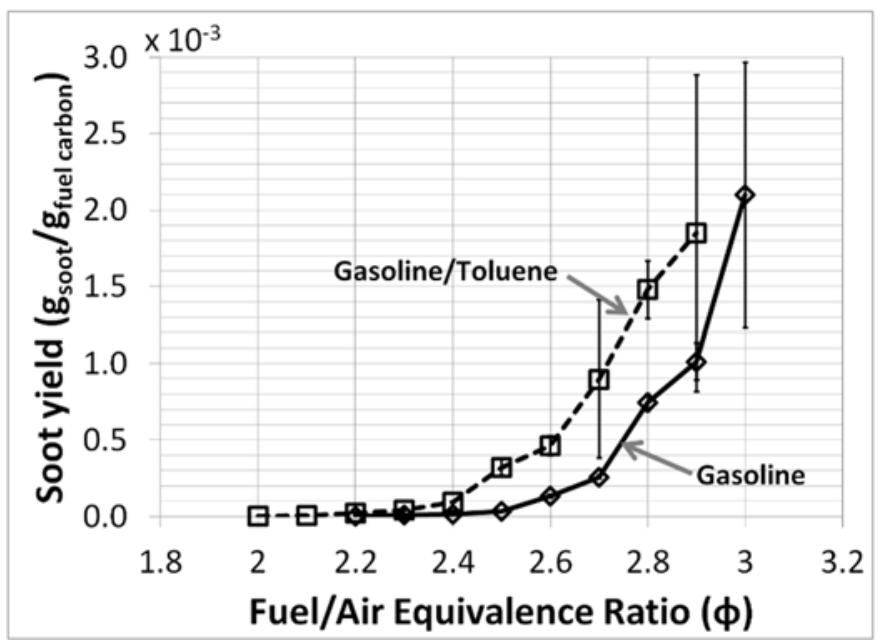

Figure 6: Soot Yield versus equivalence Ratio (charge density $=0.16 \mathrm{kmol} / \mathrm{m}^{3}$; temperature $=695 \mathrm{~K}$ )

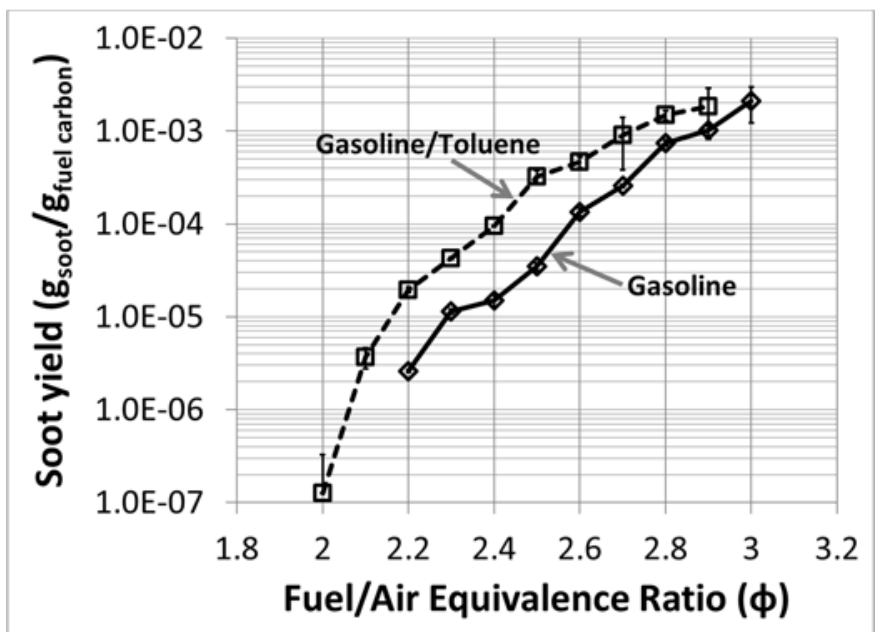

Figure 7: Soot Yield versus equivalence ratio on semi-log scale (charge density $=0.16$ $\mathrm{kmol} / \mathrm{m}^{3}$; temperature $=695 \mathrm{~K}$ ) 


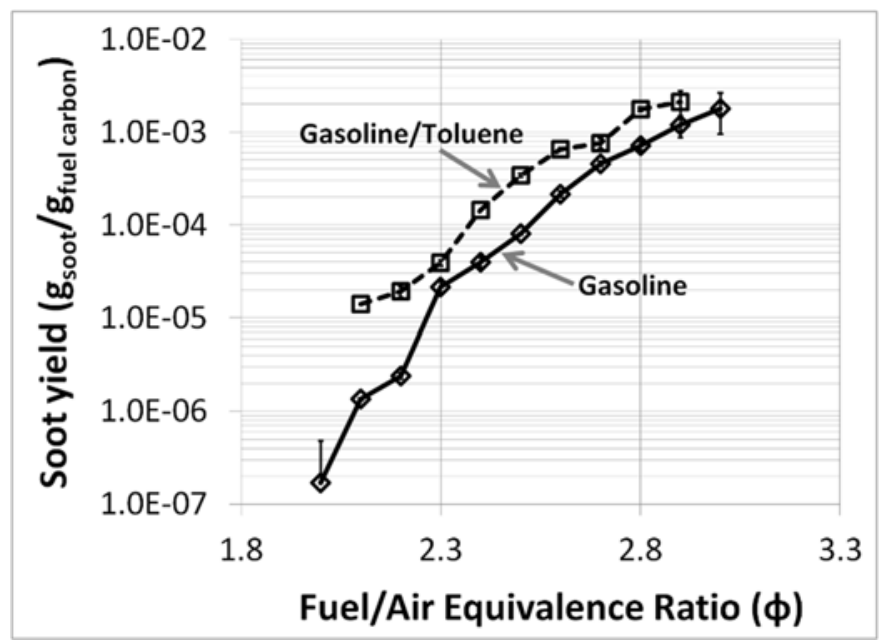

Figure 8: Soot Yield versus equivalence ratio on semi-log scale (charge density $=0.14$ $\mathrm{kmol} / \mathrm{m}^{3}$; temperature $=695 \mathrm{~K}$ )

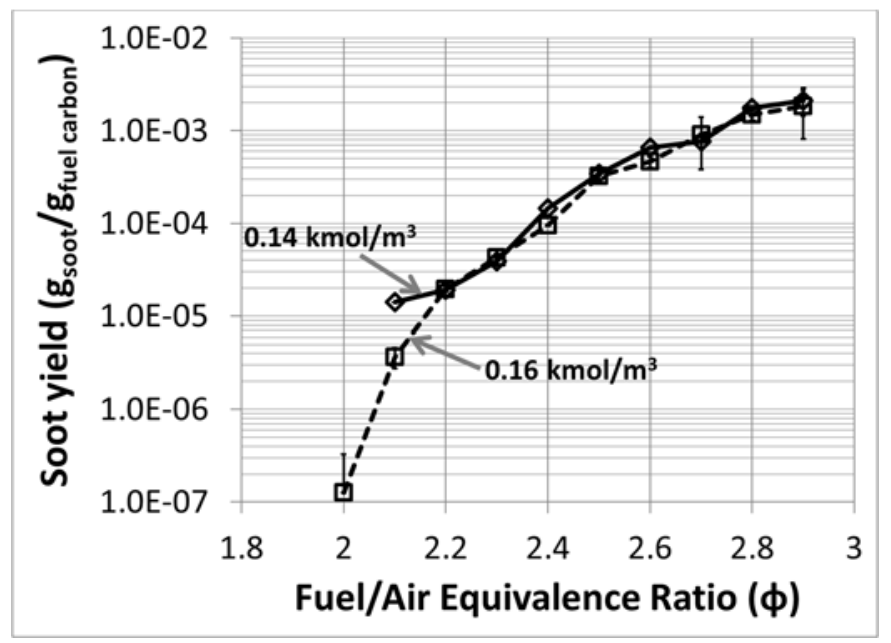

Figure 9: Soot Yield versus equivalence ratio on semi-log scale (Fuel: 20\% Toluene, by volume, in gasoline; temperature $=695 \mathrm{~K}$ ) 


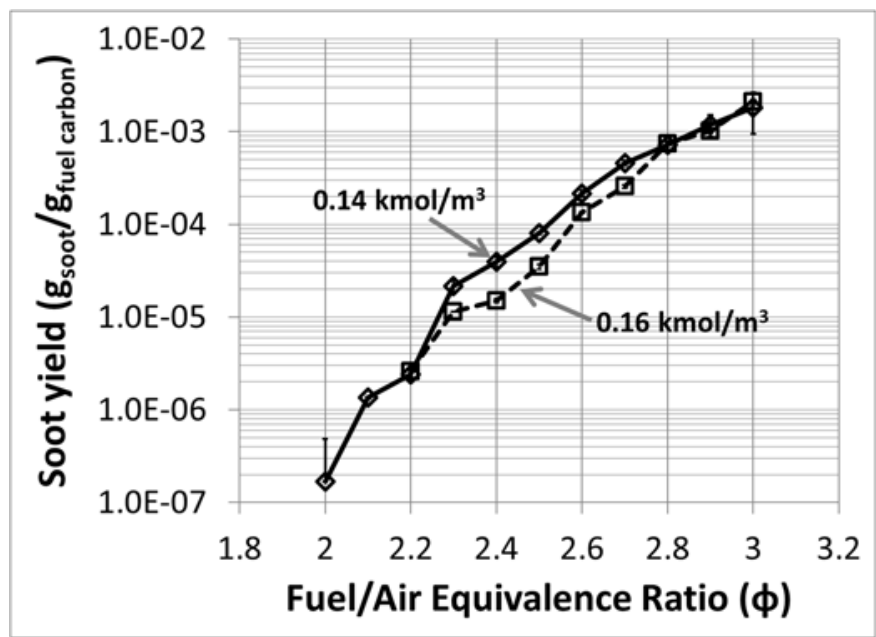

Figure 10: Soot Yield versus equivalence ratio on semi-log scale (Fuel: Gasoline; temperature $=695 \mathrm{~K}$ )

\section{Soot yield as a function of temperature}

In this experiment, the inert fraction of the mixture was varied by changing the $\mathrm{Ar} / \mathrm{N}_{2}$ ratio from 0 to 1 . This change varied the ratio of specific heats of the unburned mixture from 1.22 to 1.27 . The charge density $\left(0.16 \mathrm{kmol} / \mathrm{m}^{3}\right)$, equivalence ratio $(2.5)$ and initial charge temperature $(373 \mathrm{~K})$ were held constant. The temperature after compression then changed between $640 \mathrm{~K}$ and $725 \mathrm{~K}$. This experiment was done with the base gasoline fuel to assess the temperature sensitivity of the soot yield.

The results of this sweep are shown in Figure 11 on the semi-log scale. The soot yield decreases nearly exponentially with increasing compression temperature. The decrease is by a factor of 0.58 for every $10 \mathrm{~K}$ increase in temperature in the $640 \mathrm{~K}$ to $710 \mathrm{~K}$ range. The decrease is more rapid for temperatures above $710 \mathrm{~K}$. This observation is consistent with the soot formation behavior in premixed flames: the oxidation rate of soot precursors increases more rapidly with temperature than the soot inception rate [24]. Therefore, the sooting tendency decreases with an increase in temperature. 


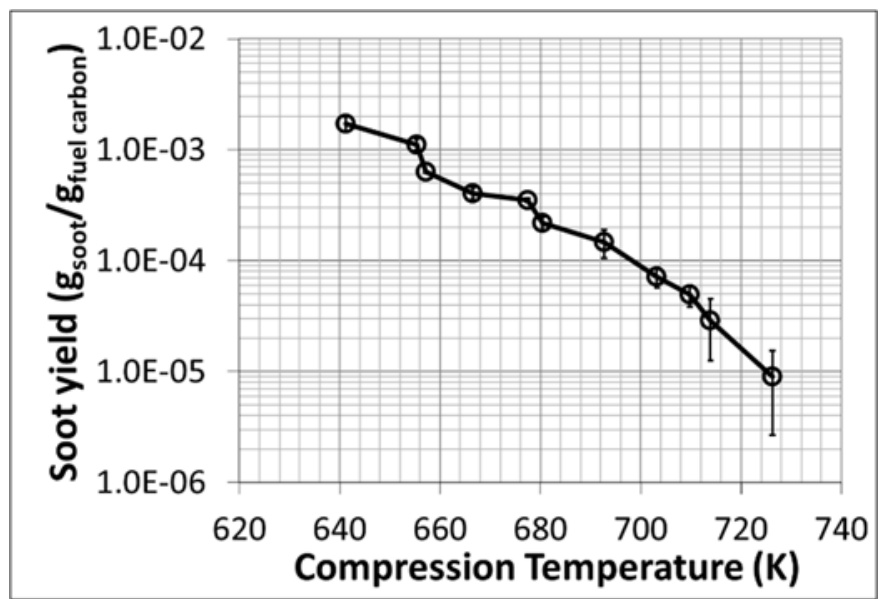

Figure 11: Soot Yield versus temperature on semi-log scale (charge density $=0.16 \mathrm{kmol} / \mathrm{m} 3 ; \varphi=2.5$ )

\section{$\Phi$ threshold for soot formation}

In the context of application to internal combustion engines, it is of interest to determine for gasoline a $\Phi$ threshold beyond which there would be significant soot formation in a homogeneous charge. The threshold would determine the mixing requirement for the fuel vapor and the charge air locally to avoid soot formation. The value could be implemented in CFD simulations for studying different mixing strategies.

The data shown above suggest that this threshold would be a function of temperature and charge density (or pressure). To determine this threshold, a soot yield of $3 \times 10^{-4}$ is used as the boundary for defining significant soot formation. Referring to Figure 6 , this value is chosen to be sufficiently high for consistent $\Phi$ threshold determination, but sufficiently low so that the soot yield increases significantly with $\Phi$ beyond the threshold.

The $\Phi$ threshold for significant soot formation is shown in Figure 12 as a function of temperature for mixture densities of $0.12,0.14$ and $0.16 \mathrm{kmol} / \mathrm{m}^{3}$ in the temperature range of 657 to $695 \mathrm{~K}$. In this range, the $\Phi$ threshold for soot formation increases approximately linearly from 2.45 to 2.65 with unburned gas temperature at a rate of 0.1 points $/ 15 \mathrm{~K}$. The rate is not sensitive to the mixture density and the threshold values at the same temperature are approximately the same. Thus, the sooting propensity of the mixture decreases with increasing temperature. This observation is consistent with the soot formation behavior in premixed flames as discussed in the previous section. 


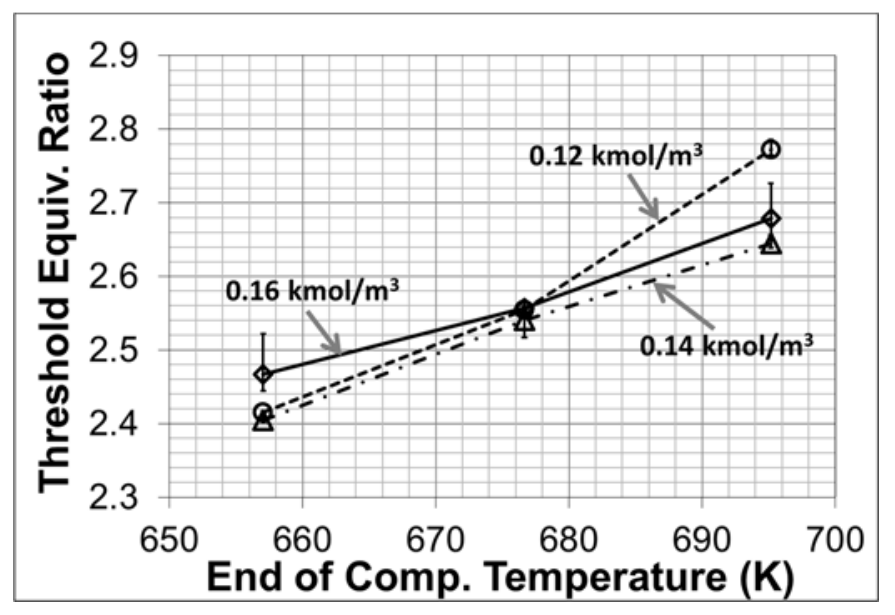

Figure 12: Effect of unburned mixture temperature on threshold equivalence ratio

The threshold data are plotted as a function of charge density in Figure 13. The threshold values do not change significantly as the charge density is varied from $0.12 \mathrm{kmol} / \mathrm{m}^{3}$ to $0.16 \mathrm{kmol} / \mathrm{m}^{3}$. The variation across this range of densities, for all the temperatures being tested, is less than 0.05 equivalence ratio. These observations suggest that the charge density had little influence on the threshold equivalence ratio for soot formation.

The insensitivity of the $\Phi$ threshold for sooting to mixture density at the same temperature is consistent with the findings of Olson and Madronich who found that soot formation (soot yields) were independent of fuel, oxidizer or diluent concentrations [25]. Haynes and Wagner also noted a relative insensitivity of soot formation threshold to pressure in premixed flames [8].

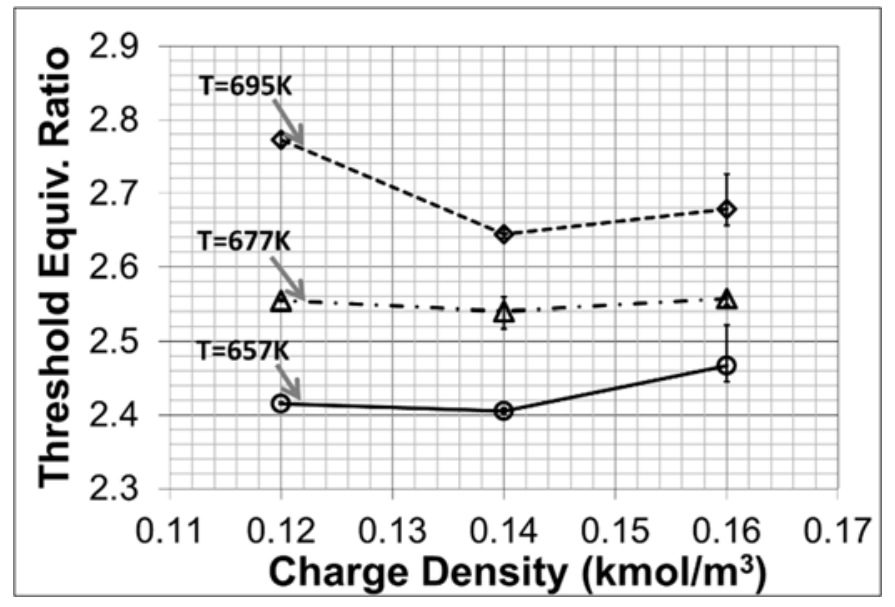

Figure 13: Charge Density Effect on Soot Formation $\Phi$ Threshold

\section{Conclusions:}


The soot yield for a homogeneous fuel air mixture has been measured in a rapid compression machine (RCM). The fuels used were a reference gasoline and a blend of that gasoline and toluene. The latter, at a liquid volume fraction of $40 \%$ aromatics versus that of $28 \%$ in the original fuel, was used to assess the sensitivity of the soot yield to the fuel aromatic content. The sensitivity of soot yield to temperature was quantified. The soot yield as a function of fuel equivalence ratio $(\Phi)$ and the $\Phi$ threshold for significant soot formation have been determined. The following conclusions are drawn:

1) At a fixed unburned gas temperature of $695 \mathrm{~K}$, the soot yield increases exponentially with $\Phi$ until $\Phi \cong 2.7$. Beyond that, the formation rate increases less rapidly. The rate of exponential increase is approximately a factor of 2.5 for every 0.1 -point increase in $\Phi$. This rate is the same for the gasoline and for the gasoline/toluene blend, and for the mixture densities of 0.14 and $0.16 \mathrm{kmol} / \mathrm{m}^{3}$.

2) In the range of $\Phi$ where the soot yield increases exponentially, the yield at the density of $0.16 \mathrm{kmol} / \mathrm{m}^{3}$ for the gasoline/toluene blend is 6 times that for the original gasoline. At density of $0.14 \mathrm{kmol} / \mathrm{m}^{3}$, the corresponding ratio is lower - approximately 4 . This difference in response is attributed solely to the soot yield sensitivity to density for the gasoline, since for the gasoline/toluene blend, the soot yields are essentially the same for the two densities.

3) The soot yield of gasoline decreases exponentially with increasing temperature. The decrease is by a factor of 0.58 for every $10 \mathrm{~K}$ increase in temperature in the $640 \mathrm{~K}$ to $710 \mathrm{~K}$ range. The decrease is more rapid for temperatures above $710 \mathrm{~K}$.

4) The equivalence ratio threshold for soot formation under fuel-rich conditions is not sensitive to the charge density in the range of 0.12 to $0.16 \mathrm{kmol} / \mathrm{m}^{3}$.

5) The soot formation $\Phi$ threshold increases (and therefore the propensity in forming soot decreases) linearly with increased unburned gas temperature. In the temperature range of $657 \mathrm{~K}$ to $695 \mathrm{~K}$, the threshold $\phi$ value increases from approximately 2.45 to 2.67 ; the rate of increase is 0.1 points for every $15 \mathrm{~K}$ rise in temperature.

Strictly speaking, the above conclusions have been drawn from only one fuel (the certification gasoline). However, being the certification fuel, it is expected that the fuel behavior should be representative of market gasolines and the conclusions should be generally valid.

\section{Declaration of Conflicting Interests}

The authors declare that there is no conflict of interest.

\section{Funding Acknowledgements}

This work was supported by the MIT Research Consortium on Engine and Fuels Research. The consortium members were BorgWarner, Ford, FCA, and GM. 


\section{References:}

[1] J. Andersson, M. Keenan and K. Akerman, "GDI Particles - Legislation, Current Levels and Control," in Cambridge Particle Meeting, Cambridge, UK, 2009.

[2] V. S. Costanzo and J. B. Heywood, "Effect of In-Cylinder Liquid Fuel Films on Engine-Out Unburned Hydrocarbon Emissions for an SI Engine," in SAE International, Detroit, 2012.

[3] J. E. Ketterer and W. K. Cheng, "On the Nature of Particulate Emissions from DISI Engines at Cold-Fast-Idle," SAE Int. J. Engines, vol. 7, no. 2, pp. 986-994, April 2014.

[4] K. Dearn, J. Xu, H. Ding, H. Xu, A. Weall, P. Kirkby, B. Cooper, I. Edington and J. Krueger-Venus, "An Investigation into the Characteristics of DISI Injector Deposits Using Advanced Analytical Methods," SAE Int. J. Fuels Lubr., vol. 7, no. 3, pp. 771-782, October 2014.

[5] P. Witze and R. Green, "LIF and Flame-Emission Imaging of Liquid Fuel Films and Pool Fires in an SI engine During a Simulated Cold Start," SAE Paper 970866, 1997.

[6] E. Stevens and R. Steeper, "Piston Wetting in an Optical DISI Engine: Fuel Films, Pool Fires, and Soot Generation," SAE Paper 2001-01-1203, 2001.

[7] P. Eastwood, Particulate Emissions from Vehicles, Wiley \& Sons, Ltd, 2008.

[8] B. S. Haynes and H. G. Wagner, "Soot Formation," Progress in Energy and Combustion Science, vol. 7, no. 4, pp. 229-273, 1981.

[9] Z. Mansurov, "Soot Formation in Combustion Processes (Review)," Combustion, Explosion, and Shock Waves, pp. 727-744, 2005.

[10] D. Tanaka, R. Uchida, T. Noda, A. Kolbeck, S. Henkel, Y. Hardalupas and A. H. Y. Taylor, "Effects of Fuel Properties Associated wiht In-Cylinder Behavior on Particulate Number from a Dirct Injection Gasoline Engine," SAE Paper 2017-011002, 2017.

[11] O. Smith, "Fundamentals of Soot Formation in Flames with Application to Diesel Engine Particulate Emissions," Prog. Energy Combust. Sci., 7, pp. 275-291, 1981.

[12] W. Pitz, N. Cernansky, F. Dryer, F. Egolfopoulos, J. Farrell, D. Friend and H. Pitsch, "Development of an Experimental Data Base and Kinetic Models for Surrogate Gasoline Fuels," SAE Paper 2007-01-0175, 2007.

[13] N. Ladommatos and H. Zhao, Engine Combustion Instrumentation and Diagnostics, SAE International, 2001.

[14] I. Kitsopanidis and W. K. Cheng, "Soot Formation Study in a Rapid Compression Machine," ASME J. of Engineering for Gas Turbines and Power, vol. 128, pp. 9422-949, 2006.

[15] K. Aikawa, T. Sakurai and J. J. Jetter, "Development of a Predictive Model for Gasoline Vehicle Particulate Matter Emissions," SAE Int. J. Fuels Lubr., vol. 3, no. 2, pp. 610-622, October 2010. 
[16] E. Chapman, M. Winston-Galant, P. Geng, R. Latigo and A. Boehman, "Alternatie Fuel Propery Correlations to the Honda Particulate Matter Index (PMI)," SAE Paper 2016-01-2250, 2016.

[17] J. Wittmann and L. Menger, "Novel Index for Evaluation of Particle Formation Tendencies of Fuels with Different Chemical Compositions," SAE Paper 2017-019380, 2017.

[18] F. Leach, R. Stone, D. Fennell, D. Hayden, D. Richardson and N. Wicks, "Predicting the Particulate Matter Emissions from Spray-Guided Gasoline DirectInjection Spark Ignition Engines," Proc. I Mech E Part D, J Automotive Engineering, vol. 23, no. 6, pp. 717-730, 2017.

[19] I. Kitsopanidis, "Experimental and computational study of soot formation under diesel engine conditions," PhD thesis, Department of Mech. Eng., MIT, Cambridge, 2004.

[20] A. Maria, W. K. Cheng, W. Cannella and K. Kar, "Fuel Factors Affecting the HighLoad Limit of a Temperature Stratified Controlled Auto-Ignition Engine," in SAE Technical Paper, Detroit, MI, 2014.

[21] P. Whitaker, P. Kapus, M. Ogris and P. Hollerer, "Measures to Reduce Particulate Emissions from Gasoline DI Engines," SAE Int. J. Engines, vol. 4, no. 1, pp. 14981512, April 2011.

[22] S. Poulos and J. Heywood, "The Effect of Chamber Geometry on Spark-Ignition Engien Combustion," in SAE Paper 830334; SAE Transactions, Vol. 92, 1983.

[23] P. Park and J. Keck, "Rapid Compression Machine Measurements of Ignition Delay Times for PRD Mixtures," in SAE Paper 900027; SAE Trans., Vol. 99, pp. 11-23, 1990.

[24] I. Glassman and R. Yetter, Combustion, 4 ed., Academic Press, 2008.

[25] D. B. Olson and S. Madronich, "The Effect of Temperature on Soot Formation in Premixed Flames," Combustion and Flame, vol. 60, no. 2, pp. 203-213, May 1985. 